Norman R. Searle MDCM, Sylvain Côté MD, Jean Taillefer MD, Michel Carrier MD, Line Gagnon IT, Micheline Roy IT, Daniel Lussier L PHARM

\title{
Propofol or midazolam for sedation and early extubation following cardiac surgery
}

Purpose: The purpose of this randomized double-blind study was to evaluate the efficacy of midazolam and propofol for postoperative sedation and early extubation following cardiac surgery.

Methods: ASA physical status II-III patientis scheduled to undergo elective first-time cardiac surgery with an ejection fraction $>45 \%$ were eligible. All patients received a standardized sufentanil/isoflurane anaesthesia. During cardiopulmonary bypass $100 \mu \mathrm{g} \cdot \mathrm{kg}^{-1} \cdot \mathrm{min}^{-1}$ propofol was substituted for isofurane. Upon arrival in the Intensive Care Unit (ICU), patients were randomized to either $10 \mu \mathrm{g} \cdot \mathrm{kg}^{-1} \cdot \mathrm{min}^{-1}$ propofol $(n=21)$ or $0.25 \mu \mathrm{g} \cdot \mathrm{kg}{ }^{-} \cdot \mathrm{min}^{1}$ midazolam $(n=20)$. Infusion rates were adjusted to maintain sedation within a predetermined range (Ramsay $2-4)$. The infusion was terminated after four hours. Patients were weaned from mechanical ventiation and their tracheas extubated when haemodynamic stability, haemostasis, normothermia and mental orientation were confirmed. Haemodynamic measurements, arterial blood gas tensions and pulmonary function tests were recorded at specified times.

Results: There were no differences between the two groups for the time spent at each level of sedation, number of infusion rate adjustments, amount of analgesic and vasoactive drugs, times to awakening and extubation. The costs of propofol were higher than those of midazolam. There were no differences in haemodynamic values, arterial blood gas tensions and pulmonary function.

Conclusion: We conclude that midazolam and propofol are safe and effective sedative agents permitting early extubation in this selected cardiac patient population but propofol costs were higher.

But: Le but de cette étude randomisée, à double insu était d'évaluer l'efficacité du midazolam et du propofol pour sédation postopératoire en vue d'une extubation précoce postchirurgie cardiaque.

Méthodologie: Tout patient ASA II-III admis pour une première chirurgie cardiaque élective ayant une fraction d'éjection $>45 \%$ était éligible. Tous les patients ont reçu une anesthésie standard à base de sufentanil/isoflurane. Durant la circulation extracorporelle, le propofol $\left(100 \mu \mathrm{g} \cdot \mathrm{kg}^{-1} \cdot \mathrm{min}^{-1}\right)$ a été substitué à l'isoflurane. Dès l'arrivée aux soins intensifs, les patients furent randomisés soit au propofol $(n=21)$ à $10 \mu \mathrm{g} \cdot \mathrm{kg}^{\prime}{ }^{\prime} \cdot \mathrm{min}^{\prime}$ ', soit au midazolam $(n=20) 0.25 \mu \mathrm{g} \cdot \mathrm{kg}^{\prime} \cdot \mathrm{min}^{-1}$. Les débits de perfusion étaient ajustés pour maintenir un niveau de sédation prédéterminée (Ramsay 2-4). La perfusion était cessée après quatre heures. Les patients étaient sevrés de la ventilation mécanique et extubés lorsque la stabilité hémodynamique, l'hémostase, la normothermie et l'orientation mentale étaient confirmées. Des bilans hémodynamiques, gaz artériels et fonction pulmonaire furent enregistrés à des intervalles spécifiques.

Résultats: II n'y avait pas de différence entre les groupes pour le temps occupé aux différents niveaux de sédation. d'ajustement de perfusion, le temps d'éveil et d'extubation. Le coût du propofol était plus élevé que celui du midazolam. La demande d'analgésique et l'utilisation d'agents vasoactifs étaient similaires. Aucune différence de fonction pulmonaire. gaz artériels et hémodynamique ria été décelée.

Conclusion: Nous concluons que le midazolam et le propofol sont sécurtaires et efficaces comme agents de sédation permettant une extubation précoce pour ce groupe de patients cardiaques sélectionnés mais le coût du propofol est plus élevé.

\footnotetext{
From the Departments of Anaesthesia, and Surgery, Montrcal Heart Institutc, Montreal, Canada.

Supported in part by a research grant from Zeneca Pharma, Mississauga, Ontario, Canada. Preliminary results of this study wcre presented at the Annual Meeting of the Society of Cardiovascular Anaesthesia, Philadelphia, PA 1994.

Address correspondence to: Dr Norman R Searle, Montreal Heart Institute, Department of Anaesthesia, 5000 Bélanger East, Montreal, Quebec HIT IC8 Canada; Phone: 514-376-3330 ext: 3732; Fax: 514-376-8784

Accepted for publication, March 22, 1997.
} 
$\mathrm{I}$ $\mathrm{N}$ the immediate postoperative period after cardiac surgery, a period of controlled mechanical ventilation and sedation is required until rewarming, haemostasis and haemodynamic stability are confirmed. The current practice, in most cardiac centres, has relied on judicious use of sedative and analgesic drugs. However, a recent review of the practice of cardiac anaesthesia with goal-directed objectives has challenged not only the use of intraoperative highdose opioids but also the need for prolonged mechanical ventilation. ${ }^{1}$ Indeed, earlier tracheal extubation and discharge from the Intensive Care Unit (ICU) without increased mortality and morbidity and with decreased overall cost have been demonstrated. ${ }^{2-6}$

Presently, benzodiazepines are amongst the most common group of drugs used and midazolam has emerged as the agent of choice in several intensive care units because of its pharmacological profile and ease of administration. However, propofol is rapidly gaining popularity since its approval for ICU sedation.

All but one ${ }^{4}$ comparative studies between propofol and midazolam for sedation of post-cardiac surgery patients have shown that patients treated with propofol can be weaned faster from mechanical ventilation and required less analgesia and adjustment in the infusion rate. $2,3,5,7$

Comparative studies between propofol and midazolam for sedation of post-cardiac surgery patients have shown that patients treated with propofol can be weaned faster from mechanical ventilation and required less analgesia and adjustment in the infusion rate. ${ }^{2-5,7}$ Unfortunately, none of the previous comparative studies were blinded, all involved prolonged ventilatory support $(>12 \mathrm{hr}$ ) and none attempted to extubate tracheas early $(<6 \mathrm{hr})$. The differences observed between propofol and midazolam may be related to the prolonged infusion of these agents with different context-sensitive halftimes. ${ }^{8}$

Therefore, this double-blind randomized study was undertaken to determine and compare the effectiveness, safety and dosage requirements of propofol and midazolam for short-term sedation and early extubation following cardiac surgery.

\section{Methods}

Following Institutional Review and Biocthics Committee approval, written informed consent was obtained from 47 patients undergoing cardiac surgery. All adult ASA physical status II-III patients aged 18-70 yr, undergoing elective first time coronary artery bypass graft surgery (CABG), single-valve replacement, or correction of atrial septal defect were eligible for inclusion. Exclusion criteria included poor left ventricular (LV) function (ejection fraction
$<0.45$ ), combined CABG and valvular replacement, patients requiring inotropic or mechanical support prior to surgery. Patients with a history of alcohol or drug abuse, clinically significant hepatic, renal or psychiatric diseases or known allergy to either study drug were also excluded. Patients were randomized in blocks of four if they successfully weaned from cardiopulmonary bypass (CPB) with a cardiac index $>2.0$ $\mathrm{L} \cdot \mathrm{min}^{-1} \cdot \mathrm{m}^{-2}$. Postoperative exclusion criteria were: the presence of cardiac index $<2.0 \mathrm{~L} \cdot \mathrm{min}^{-1} \cdot \mathrm{m}^{-2}$ with adequate filling pressure and requiring inotropic support or excessive bleeding ( $>300 \mathrm{~mL} \cdot \mathrm{hr}^{-1}$ ) for two consecutive hours during the period of study.

All patients received a standard premedication consisting of $2 \mathrm{mg}$ lorazepam $s \mathrm{l}$ and $0.15 \mathrm{mg} \cdot \mathrm{kg}^{-1}$ morphine im given 90 and $30 \mathrm{~min}$ respectively before the procedure. All usual cardiac medications required by the patient's underlying condition were also continued. Following preoxygenation, anaesthesia was induced with 1-2 $\mu \mathrm{g} \cdot \mathrm{kg}^{-1}$ sufentanil and supplemented with isoflurane. A continuous sufentanil infusion at 0.5 $\mu \mathrm{g} \cdot \mathrm{kg}^{-1} \cdot \mathrm{hr}^{-1}$ was initiated after induction and maintained until onset of CPB. Afterward, the sufentanil infusion was decreased to $0.25 \mu \mathrm{g} \cdot \mathrm{kg}^{-1} \cdot \mathrm{hr}^{-1}$ until the end of surgery. Cardiopulmonary bypass was done under mild hypothermia $\left(32-34^{\circ} \mathrm{C}\right)$ with a membrane oxygenator. Cold blood cardioplegia was used to arrest the heart. All patients were rewarmed till bladder temperature returned to $36^{\circ} \mathrm{C}$. During $\mathrm{CPB}, 100 \mu \mathrm{g} \cdot \mathrm{kg}^{-1} \cdot \mathrm{min}^{-1}$ propofol was substituted for isoflurane. Before and after $\mathrm{CPB}$, isoflurane was titrated as required to keep systolic blood pressure and heart rate within $\pm 20 \%$ of baseline ward measurements (average of three to five ward measurements). Systolic blood pressure $>120 \%$ of baseline or $>160 \mathrm{mmHg}$, if not responsive to deepening with isoflurane, was treated with nitroglycerine $i v$. Ischaemia was treated with nitroglycerine $i v$ in the absence of any haemodynamic change. Systolic blood pressure $<80 \%$ of baseline or $<90 \mathrm{mmHg}$ was corrected using iv fluids, decreasing isoflurane concentration and/or decreasing the sufentanil infusion and, if necessary, small boluses of ephedrine or phenylephrine were used. Intravenous metoprolol was used to maintain heart rate $<+20 \%$ of baseline or $<100 \mathrm{bpm}$ throughout the operative period. Sinus bradycardia (heart rate $<50 \mathrm{bpm}$ ) was treated with glycopyrrolate. Electrocardiographic episodes of ischaemia were defined as: 1) horizontal or downsloping ST segment depression from baseline of $1 \mathrm{~mm}$ lasting at least one minute and separated from other episodes by zl min; 2) ST segment elevation from baseline $22 \mathrm{~mm}$ measured at the J point lasting at least one minute and separated from other episodes by $\geq 1 \mathrm{~min}$. Neuromuscular blockade was achieved with $0.1 \mathrm{mg} \cdot \mathrm{kg}^{-1}$ pancuronium at induction and prior to $\mathrm{CPB}$. Muscle relaxation 
was reversed with neostigmine and glycopyrrolate at the end of surgery. Indomethacin, $100 \mathrm{mg} \mathrm{pr}$, was given at the end of surgery.

Immediately on arrival in the ICU, patients received either propofol or midazolam. To maintain a doubleblind protocol, each patient received simultaneously two infusions at identical rate determined by the pharmacist who prepared the study medications. Patients randomized to the propofol group received an infusion of propofol plus an infusion of normal saline (placebo) whereas patients randomized to the midazolam group received an infusion of midazolam plus an infusion of Intralipid solution (placebo). All drugs or placebo were prepared in identical bags. Appropriate dilution of propofol and midazolam was done to obtain comparable infusion rates. Propofol and placebo were started at a dose of $10 \mu \mathrm{g} \cdot \mathrm{kg}^{-1} \cdot \mathrm{min}^{-1}$. Adjustment in propofol and placebo infusions by increments of $10 \mu \mathrm{g} \cdot \mathrm{kg}^{-1} \cdot \mathrm{min}^{-1}$ were permitted every $10 \mathrm{~min}$ to maintain an appropriate level of sedation. The midazolam and placebo infusions were started at a dose of $0.25 \mu \mathrm{g} \cdot \mathrm{kg}^{-1} \cdot \mathrm{min}^{-1}$ and both were adjusted every $10 \mathrm{~min}$ by an increase of $0.25 \mu \mathrm{g} \cdot \mathrm{kg}^{-1} \cdot \mathrm{min}^{-1}$ when needed. Analgesia was provided with an infusion of morphine at $0.02 \mathrm{mg} \cdot \mathrm{kg}^{-1} \cdot \mathrm{hr}^{-1}$ and was started at arrival in the ICU. If analgesia was inadequate, boluses of $2 \mathrm{mg}$ morphine q $5 \mathrm{~min}$ prn were administered until pain was relieved. The level of sedation was assessed by the same research assistant throughout the study with the goal of maintaining sedation level between 2 and 4 on the sedation scale described by Ramsay et al. ${ }^{9}$ After four hours, the infusion was stopped and patients were weaned from mechanical ventilation if they met the following criteria: normothermia $\left(>36^{\circ} \mathrm{C}\right)$, bleeding $<100 \mathrm{~mL} \cdot \mathrm{hr}^{-1}$, heart rate $<100 \mathrm{bpm}$, systolic blood pressure $<140 \mathrm{mmHg}$, patient oriented and with adequate pain control. Postoperative hypertension (systolic blood pressure
$>140 \mathrm{mmHg}$ ) was treated with nitroprusside $i v$. The use of prophylactic nitroglycerine was permitted according to existing postoperative surgical protocol (prevention of mammary graft spasm).

Time to awakening (from end of surgery), time to extubation (from end of infusion), time spent at each level of sedation, number of adjustments required to maintain an appropriate level of sedation, dose of morphine, as well as incidences of nausea, vomiting and shivering were recorded. Haemodynamic measurements included systemic and pulmonary pressures, heart rate, central venous and pulmonary artery occlusion pressures and cardiac indices on arrival in the ICU and at specified times throughout the postoperative period. Arterial blood gas tensions and pulmonary functions were determined before induction and after extubation.

Statistical analysis was performed using $t$ test for normally distributed numerical data. Chi square and Fisher's exact test were used for nominal data. A $P$ value $<0.05$ was considered significant. Using previously published data ${ }^{3,5,7}$ for time to spontaneous ventilation and/or time to extubation, a difference of one hour would require a sample size of 20 patients per group to achieve a power of $80 \%$ with an $\alpha$ of 0.05 .

\section{Results}

From the total of 47 patients initially recruited in the study, six patients were excluded, leaving 20 in the midazolam group and 21 in the propofol group for analysis of results. Three patients were excluded because of excessive postoperative bleeding (two midazolam and one propofol), two other patients because of haemodynamic instability (not randomized) and one operation was cancelled preoperatively by the surgeon. There were no differences between the two groups with regards to age, weight, height and sex distribution (Table I). There were also no

TABLE I Patient demographics and intraoperative data (mean \pm SD)

\begin{tabular}{llll}
\hline & Midazolam & Propofol & $P$ \\
\hline & $(\mathrm{n}=20)$ & $(\mathrm{n}=21)$ & \\
Age (yr) & $\mathbf{5 5 . 7} \pm 8.0$ & $51.2 \pm 10.0$ & NS \\
Sex M:F & $14: 6$ & $14: 7$ & NS \\
Weight $(\mathrm{kg})$ & $75.5 \pm 14.9$ & $71.8 \pm 11.3$ & NS \\
Height $(\mathrm{cm})$ & $166.5 \pm 8.5$ & $165.8 \pm 8.2$ & NS \\
Type of operation & & & \\
- CABG & 12 & 13 & NS \\
- Valvular & 8 & 7 & NS \\
- ASD & - & 1 & NS \\
Duration of operation (min) & $191.2 \pm 34.0$ & $184.0 \pm 32.5$ & NS \\
Duration of CPB (min) & $72.2 \pm 24.6$ & $63.5 \pm 16.8$ & NS \\
Discharge time (D) & & & \\
- ICU & $3.9 \pm 1.7$ & $3.7 \pm 1.7$ & NS \\
- Hospital & $7.8-2.7$ & $7.2 \pm 1.7$ & NS \\
\hline
\end{tabular}

$M=$ male $; \mathrm{F}=$ female NS = not significant $\mathrm{CABG}=$ coronary artery bypass graft; $\mathrm{ASD}=$ atrial septal defect; $\mathrm{CPB}$ = cardiopulmonary bypass. 
differences in the type of surgery, duration of operation, extracorporeal circulation, cross-clamp time and ICU and hospital discharge time (Table I). The average infusion rate of midazolam was $0.25 \pm 0.02 \mu \mathrm{g} \cdot \mathrm{kg}^{-1} \cdot \mathrm{min}^{-1}$ while that of propofol was $10.6 \pm 2.9 \mu \mathrm{g} \cdot \mathrm{kg}^{-1} \cdot \mathrm{min}^{-1}$ (Table II). The mean infusion cost of propofol was higher than the cost of midazolam (Table II).

The percentage of time spent at any level of sedation is outlined in Figure 1. In the midazolam group, $65.4 \%$ of the sedation time was spent at the desired level (level 2-4) vs $67 \%$ in the propofol group $(P=$ NS). The level of sedation was easily controlled in both groups. Two patients in the midazolam group and six in the propofol group needed adjustment in the infusion rate $(P=\mathrm{NS})$. There was no difference in the time to weaning and tracheal extubation following termination of sedation (midazolam 9l.5 $\pm 59 \mathrm{~min}$ to propofol $87.5 \pm 65 \mathrm{~min}, P=\mathrm{NS}$ ). The average total dose of morphine during the first four hours after surgery was $4.9 \pm 3.9 \mathrm{mg}$ and $3.9 \pm 2.5 \mathrm{mg}$ for the midazolam and propofol groups respectively $(P=\mathrm{NS})$.

Table III shows the average time to awakening, time to extubation and the respiratory data of both groups before and after extubation. No differences were found between the two groups, no patient required tracheal reintubation.

During the infusion and the subsequent $16 \mathrm{hr}$ after cessation, there were no differences in haemodynamic variables (Figures 2 and 3 ). The incidence of postoperative hypertension and hypotension was similar in both groups. In the midazolam group, $40 \%$ of the patients received nitroprusside and $70 \%$ received nitroglycerine ws $33 \%$ and $67 \%$ respectively in the propofol group $(P=\mathrm{NS})$.

TABLE II Drug administration data

\begin{tabular}{|c|c|c|}
\hline & Midazolam & Propofol \\
\hline \multicolumn{3}{|l|}{ Rate of administration } \\
\hline$-\operatorname{mean}\left(\mu \mathrm{g} \cdot \mathrm{kg}^{-1} \cdot \min ^{-1}\right)$ & $0.25 \pm 0.02$ & $10.6 \pm 2.9$ \\
\hline - range $\left(\mu \mathrm{g} \cdot \mathrm{kg}^{-1} \cdot \mathrm{min}^{-1}\right)$ & $(0.23-0.48)$ & $(7.1-32.4)$ \\
\hline \multicolumn{3}{|l|}{ Total amount of study drug } \\
\hline - mean (mg) & $4.6 \pm 1.0$ & $181.2 \pm 42.3$ \\
\hline - range (mg) & $(2.87-6)$ & $(100-300)$ \\
\hline \multicolumn{3}{|l|}{ Intraoperative sufentanil } \\
\hline$\left(\mu \mathrm{g} \cdot \mathrm{kg}^{-1} \cdot \mathrm{hr}^{-1}\right)$ & $1.0 \pm 0.33$ & $1.0 \pm 0.31$ \\
\hline \multicolumn{3}{|l|}{ Postoperative morphine } \\
\hline - mean (mg) & $4.93 \pm 3.2$ & $3.94 \pm 2.6$ \\
\hline - range (mg) & $(1-14)$ & $(0.6-9.2)$ \\
\hline Acquisition cost ${ }^{*}\left(\$ C A N \cdot m^{-1}\right)$ & 0.612 & 0.048 \\
\hline Mean infusion $\operatorname{cost}^{\dagger}(\$ C A N)$ & $2.82 \pm 0.61$ & $8.49 \pm 2.03^{\star *}$ \\
\hline Range $^{\ddagger}(\$ C A N)$ & $(1.76-3.67)$ & $(4.80-14.40)$ \\
\hline
\end{tabular}

* Propofol costs $\$ 9.37$ per $200 \mathrm{mg}$; Midazolam $\$ 6.12$ per $10 \mathrm{mg}$ vial.

$\dagger$ Infusion costs were calculated by the product of the mean total study drug $\times$ acquisition cost. ₹ The range of infusion costs was calculated by the product of the range of total study drug administered $x$ acquisition cost.

${ }^{\star \star} P<0.01$

TABLE III Recovery characteristics and respiratory data (mean $\pm S D$ )

\begin{tabular}{|c|c|c|c|}
\hline & Midazolam & Propofol & $P$ \\
\hline & $(n=20)$ & $(n=21)$ & \\
\hline Time to awakening* $(\min )$ & $93.8 \pm 61.4$ & $88.6 \pm 51.0$ & NS \\
\hline Time to extubation ${ }^{\dagger}(\mathrm{min})$ & $91.5 \pm 59.4$ & $87.5 \pm 65.4$ & NS \\
\hline FVC preop (L) & $3.3 \pm 0.6$ & $3.3 \pm 0.7$ & NS \\
\hline $\mathrm{FEV}_{\mathrm{L}}$ preop (L) & $2.9 \pm 0.7$ & $3.0 \pm 1.0$ & NS \\
\hline FVC postop (L) & $1.0 \pm 0.4$ & $1.1 \pm 0.6$ & NS \\
\hline $\mathrm{FEV}_{1}$ postop (L) & $1.1 \pm 0.7$ & $1.0 \pm 0.6$ & NS \\
\hline $\mathrm{PaO}_{2}$ during $\mathrm{CPAP}(\mathrm{mmHg})$ & $130.3 \pm 47.1$ & $134.5 \pm 35.4$ & NS \\
\hline $\mathrm{PaO}_{2}$ after extubation $(\mathrm{mmHg})$ & $130.9 \pm 48.8$ & $148.7 \pm 67.5$ & NS \\
\hline $\mathrm{PaCO}_{2}$ during $\mathrm{CPAP}(\mathrm{mmHg})$ & $47.6 \pm 3.2$ & $47.1 \pm 4.4$ & NS \\
\hline $\mathrm{PaCO}_{2}$ after extubation $(\mathrm{mmHg})$ & $49.8 \pm 4.4$ & $49.1 \pm 6.0$ & NS \\
\hline
\end{tabular}

NS = not significant; * $=$ time to awakening from end of surgery, ${ }^{\dagger}=$ time to extubation from termination of infusion, FVC $=$ forced vital capacity; $\mathrm{FEV}_{1}=$ forced expiratory volume in $1 \mathrm{sec}$ ond; $\mathrm{PaO}_{2}=$ arterial oxygen partial pressure; $\mathrm{PaCO}_{2}=$ arterial carbon dioxide partial pressure; $\mathrm{CPAP}=$ continuous positive airway pressure. 


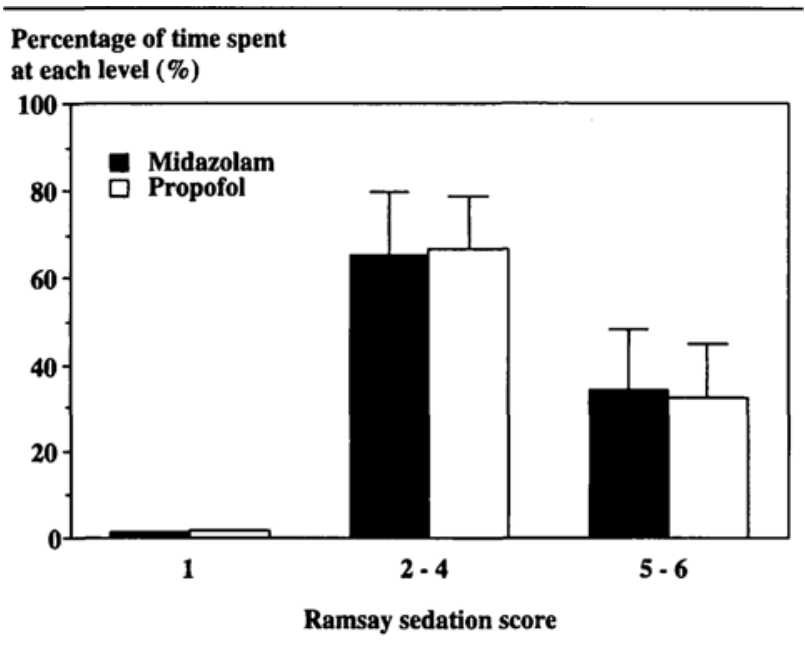

FIGURE 1 Percentage of time spent at each sedation level during sedation drug infusion.
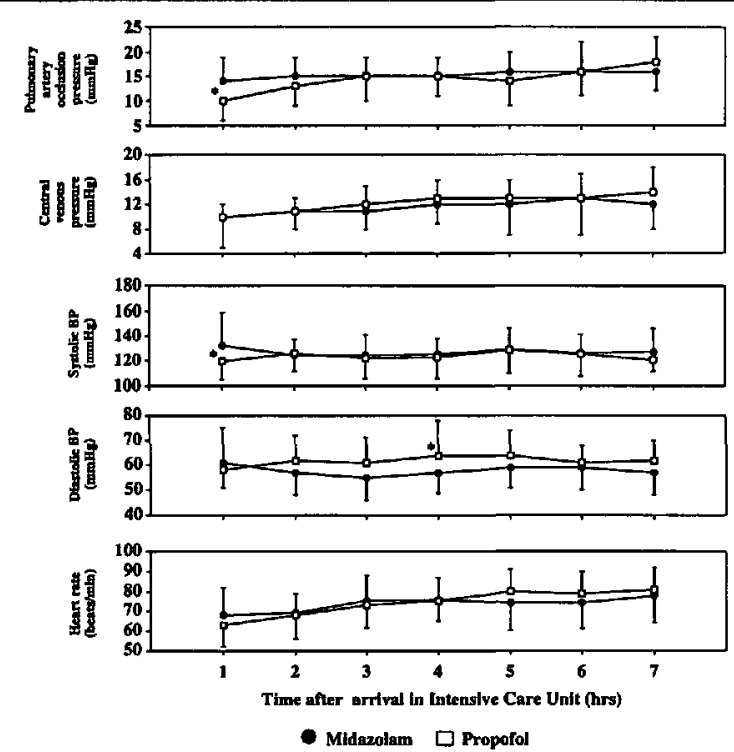

FIGURE 2 Changes in haemodynamic variables postoperatively (mean $\pm \mathrm{SD}) ;{ }^{\star} P<0.05$.

TABLE IV Postoperative events in the first $24 \mathrm{hr}$ (mean \pm SD)

\begin{tabular}{|c|c|c|c|}
\hline & Midazolam & Propofol & $P$ \\
\hline CK-MB yalue (U. ${ }^{-1}$ ) & $(n=20)$ & $(n=21)$ & \\
\hline $\begin{array}{l}\text { - at } 8 \mathrm{hr} \\
\text { - at } 16 \mathrm{hr} \\
\text { - at } 24 \mathrm{hr} \\
\text { Blood loss }(\mathrm{ml})\end{array}$ & $\begin{array}{l}33.4 \pm 24.4 \\
25.7 \pm 25.2 \\
17.7 \pm 6.1\end{array}$ & $\begin{array}{l}31.3 \pm 15.9 \\
20.8 \pm 13.7 \\
21.5 \pm 11.6\end{array}$ & $\begin{array}{l}\text { NS } \\
\text { NS } \\
\text { NS }\end{array}$ \\
\hline $\begin{array}{l}\text { - first } 3 \mathrm{hr} \\
\text { - total } \\
\text { Incidence of shivering: }\end{array}$ & $\begin{array}{l}367.6 \pm 225.1 \\
885.0 \pm 652.2\end{array}$ & $\begin{array}{l}345.8 \pm 243.8 \\
890.3 \pm 656.1\end{array}$ & $\begin{array}{l}\text { NS } \\
\text { NS }\end{array}$ \\
\hline $\begin{array}{l}\mathrm{n}(\%) \\
\text { Incidence of nausea: }\end{array}$ & $1(5 \%)$ & $2(10 \%)$ & NS \\
\hline $\mathrm{n}(\%)$ & $9(45 \%)$ & $6(29 \%)$ & NS \\
\hline
\end{tabular}

NS= not significant
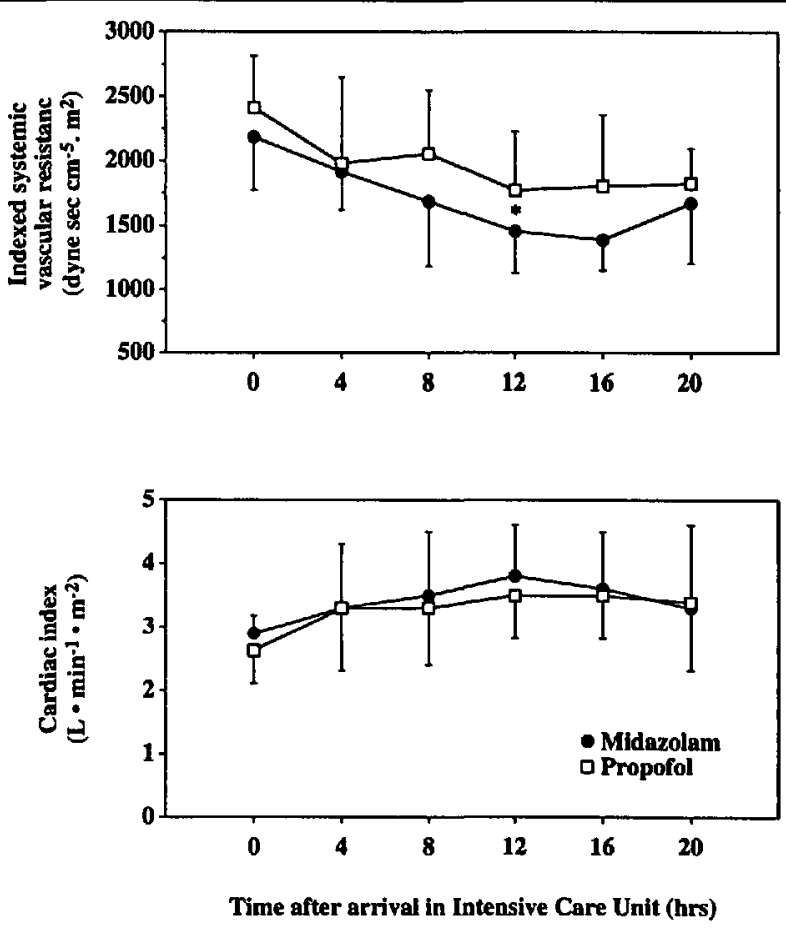

FIGURE 3 Changes in cardiac index and systemic vascular resistance index postoperatively $($ mean $\pm \mathrm{SD}) ;{ }^{*} P<0.05$.

The incidence of nausea, shivering, postoperative blood loss and CK-MB values in the first $24 \mathrm{hr}$ are shown in Table IV $(P=\mathrm{NS})$.

\section{Discussion}

Time spent in the ICU is one of the most expensive aspects of hospital care for cardiac surgery and is influenced by the duration of mechanical ventilation. It has previously been shown that patients with good preoperative left ventricular function have recovered $90 \%$ of baseline myocardial function by four hours after surgery. ${ }^{10}$ With attention to adequate analgesia and rewarming, and the avoidance of long-acting respiratory depressants, the trachea could be extubated early in the majority of CABG, the patient's trachea could be extubated early. ${ }^{11}$ Although extubation soon after surgery is desirable, it is still necessary to provide a controllable and adequate amount of sedation and analgesia in the first few hours after arrival in the ICU until rewarming, haemostasis and haemodynamic stability are confirmed.

The primary objective of this study was to evaluate the sedation profile of midazolam and propofol for early extubation following cardiac surgery. Both midazolam and propofol provided equally effective sedation in low risk patients undergoing uncomplicated cardiac surgery without delaying extubation. After arrival in the ICU, the residual effect of anaesthesia most likely explains the percentage of sedation time spent at levels 5 and 6 
(Figure 1) and the very low dose of sedative and analgesic drugs required: midazolam $\left(0.25 \mu \mathrm{g} \cdot \mathrm{kg}^{-1} \cdot \mathrm{min}^{-1}\right)$, propofol (10.6 $\mu \mathrm{g} \cdot \mathrm{kg}^{-1} \cdot \mathrm{min}^{-1}$ ) and morphine (1.1 $\left.\mathrm{mg} \cdot h \mathrm{r}^{-1}\right)$. Although the dose of intraoperative opioid in our study was relatively low, this is in agreement with previously reported high levels of sedation in the immediate postoperative period. ${ }^{3}$

Patients emerged (opened eyes spontaneous) from anaesthesia within a mean of $1.5 \mathrm{hr}$ from end of surgery and were easily maintained at the required sedation level with either drugs. Extubation was carried out in most patients within two hours of cessation of the infusion (four patients in each group required more time). Arterial blood gas tensions during continuous positive airway pressure and after extubation were similar and did not suggest greater residual depression of alveolar ventilation with either drug.

Contrary to published findings, ${ }^{3,5}$ our results failed to show any differences in favour of propofol for time to awakening, time to extubation, or analgesic requirement. This discrepancy most likely relates to differences in study protocols. Differences between the two drugs may not have become apparent in our study because of the low concentrations and short duration of infusion. Although Higgins et al. ${ }^{4}$ did not find any difference for tracheal extubation and ICU discharge times with similar infusion rates for $12 \mathrm{hr}$ this is in contrast to other studies where higher intraoperative opioid doses and/or prolonged infusion of sedative agents were used. ${ }^{3,5,7}$ The difference in extubation time is probably governed more by residual operative opioids than by the study drugs. In addition, other pharmacokinetic factors may explain the prolonged sedation associated with midazolam. Midazolam accumulation occurs in ICU patients ${ }^{12-15}$ and the clearance of midazolam is decreased and its elimination half-life increased after cardiac surgery. ${ }^{16}$ This contrasts with the rapid decline in propofol blood concentration after termination of prolonged infusion in ICU patients and the absence of pharmacokinetic changes with CPB. ${ }^{17-19}$

The low requirement for analgesics was similar in both groups, and this does not support an intrinsic analgesic action of propofol. ${ }^{4,5}$ This may relate to residual effects of intraoperative sufentanil and indomethacin given at the end of surgery.

Higgins $e t a l^{4}$ showed that patients receiving propofol had more haemodynamic variations and required less nitroprusside than patients receiving midazolam after cardiac surgery. Like others, ${ }^{3,5,7}$ we were unable to show any differences in nitroprusside requirement and haemodynamic effects with propofol. The overall incidence of hypertension and hypotension was low and no patients in either group suffered perioperative myocardial infarction.
Our pharmacoeconomic analysis consisted of a cost-minimization study. ${ }^{20}$ Cost-minimization analysis is conducted when outcomes or consequences of two or more interventions are considered to be equal. We found that propofol was more expensive than midazolam but was without added clinical benefit for shortterm post-CABG sedation. At the current rate for CABG in Canada of $\$ 20,000^{6}$ the use of propofol would have added $0.03 \%$ to the overall cost: this difference will not impact on the hospital budget. Other modalities to early tracheal extubation must be made to reduce costs and improve resource use such as decrease length of stay in ICU and hospital. ${ }^{6}$

\section{Study limitations}

Although no clinically significant differences were found between midazolam and propofol in this study, these results may only be valid and applicable for a selective patient population and clinical situation. All the patients were low risk without serious co-morbidity. The anaesthetic regimen was designed to avoid lingering effects of such drugs. No benzodiazepine was administered intraoperatively.

Until the results of further investigations are available, early extubation may be inappropriate for patients with low physiological reserve, important comorbidity, or those having more complex surgery. This brittle patient population would most likely require analgesia and sedation for prolonged mechanical ventilation and one of the study drugs may then prove to be superior.

The use of the Ramsay sedation scale also has some limitations. The scale is a compromise between accuracy, simplicity and ease of use. As a result, most scores do not differentiate between sedation, anxiety, depression and pain, but provide an estimate of overall patient comfort. ${ }^{21}$

Because of the strict requirements of therapeutic equality, cost-minimization is not commonly used to assess drug therapies. However, this method can be useful when assessing the cost difference between two drugs for which patient outcomes have been shown to be the same. Our cost-minimization study did not account for hospital costs and charges, preparation time and drug wastage. Nevertheless, all endpoints and ICU and ward management were equal. No costs difference could be attributed to drug preparation and administration because both required the same time for preparation and were administered by a similar infusion device. Drug wastage could have imparted a higher cost to propofol because of the availability of propofol in $\mathbf{2 0}$ $\mathrm{ml}$ vial that must be discarded if unused while midazolam is available in multidosage vial. 
In providing anxiolysis and analgesia during postoperative care, anaesthetists frequently administer two or three different drugs. In this study, the combined infusion of morphine contributed to our sedation therapy. We conclude that, for early extubation in lowrisk cardiac patients, the use of either midazolam or propofol is safe and effective when used in the context of this study protocol.

\section{References}

1 Hall RI. Anaesthesia for coronary artery surgery - a plea for a goal-directed approach. Can J Anaesth 1993; 40: 1178-94.

2 Karski JM, Teasdale SJ, Cheng D, Bailey K, Carroll J, Harley $P$. Recovery time following short term sedation with propofol after cardiac surgery. Can J Anacsth 1994; 41: A40.

3 Snellen $F$, Lauwers $P$, Demeyere $R$, Byttebier $G$, Van $A k e n H$. The use of midazolam versus propofol for short-term sedation following coronary artery bypass grafting. Intensive Care Med 1990; 16: 312-6.

4 Higgins TL, Yared J-P, Estafanous FG, Coyle JP, Ko $H K$, Goodale $D B$. Propofol versus midazolam for intensive care unit sedation after coronary artery bypass grafting. Crit Care Med 1994; 22: 1415-23.

5 McMurray TJ, Collier PS, Carson IW, Lyons SM, Elliott $P$. Propofol sedation after open heart surgery. A clinical and pharmacokinetic study. Anaesthesia 1990; 45 : 322-6.

6 Cheng DCH, Karski J, Peniston C, et al. Early tracheal extubation after coronary artery bypass graft surgery reduces costs and improves resource use. A prospective, randomized, controlled trial. Anesthesiology 1996; 85: 1300-10.

7 Grounds RM, Lalor JM, Lumley J, Royston D, Morgan $M$. Propofol infusion for sedation in the intensive care unit: preliminary report. BMJ 1987; 294: 397-400.

8 Hughes MA, Glass PSA, Jacobs JR. Context-sensitive half-time in multicompartment pharmacokinetic models for intravenous anesthetic drugs. Anesthesiology 1992; 76: 334-41.

9 Ramsay MAE, Savege TM, Simpson BRJ, Goodwin R. Controlled sedation with alphaxalone-alphadolone. BMJ 1974; 2: 656-9.

10 Mangano DT. Biventricular function after myocardial revascularization in humans: deterioration and recovery patterns during the first 24 hours. Anesthesiology 1985; 62: 571-7.

11 Kirklin JW, Akins CW, Blackstone EH, et al. ACC/AHA guidelines and indications for coronary artery bypass graft surgery. A report of the American College of Cardiology/American Heart Association Task Force on assessment of diagnostic and therapeutic cardiovascular procedures (subcommittee on coronary artery bypass graft surgery). Circulation 1991; 83: 1125-73.

12 Dirksen MSC, Vree TB, Driessen JJ. Clinical pharmacokinetics of long-term infusion of midazolam in critically ill patients - preliminary results. Anaesth Intensive Care 1987; 15: 440-4.

13 Byatt CM, Lewis LD, Dawling S, Cochrane GM. Accumulation of midazolam after repeated dosage in patients receiving mechanical ventilation in an intensive care unit. BMJ 1984; 289: 799-800.

14 Malacrida R, Fritz ME, Suter PM, Crevoisier C. Pharmacokinetics of midazolam administered by continuous intravenous infusion to intensive care patients. Crit Care Med 1991; 20: 1123-6.

15 Shelly MP, Mendel L, Park GR. Failure of critically ill patients to metabolise midazolam. Anaesthesia 1987; 42: 619-26.

16 Mathews HML, Carson IW, Collier PS, et al. Midazolam sedation following open heart surgery. $\mathrm{Br} \mathrm{J}$ Anaesth 1987; 59: 557-60.

17 Bailie GR, Cockshott ID, Douglas EJ, Bowles BJM. Pharmacokinetics of propofol during and after long term continuous infusion for maintenance of sedation in ICU patients. Br J Anaesth 1992; 68: 486-91.

18 Albanese J, Martin C, Lacarelle B, Saux P, Durand A, Gouin F. Pharmacokinetics of long-term propofol infusion used for sedation in ICU patients. Anesthesiology 1990; 73: 214-7.

19 Massey NJA, Sherry KM, Oldroyd S, Peacock JE. Pharmacokinetics of an infusion of propofol during cardiac surgery. Br J Anaesth 1990; 65: 475-9.

20 Jolicoeur LM, Jones-Grizzle AJ, Boyer JG. Guidelines for performing a pharmacoeconomic analysis. Am J Hosp Pharm 1992; 49: 1741-7.

21 Geddes SM, Gray WM, Asbury AJ. Skin conductance responses in patients sedated with midazolam or propofol. Br J Anaesth 1994; 73: 345-9. 